\title{
A Method for Corn-Sirup Analysis Involving Selective Adsorption
}

\author{
Emma J. McDonald and Roger E. Perry, Jr.
}

\begin{abstract}
A chromatographic method is described for the separation of corn sirups into dextrose, maltose, and dextrin fractions. The sample is adsorbed on a Darco column; separation of the components is effected by using water, a 5-percent-ethanol-in-water solution and a 15-percent-ethanol-in-water solution as eluting media. Pressure is used to increase the flow rate.
\end{abstract}

\section{Introduction}

The separation of carbohydrate mixtures on columns of carbon has received wide application in the isolation and purification of sugars during the past 5 years. ${ }^{1}$ Tiselius $[1],{ }^{2}$ using charcoal as an adsorbent, separated mixtures containing glucose and lactose, glucose and sucrose, and maltose and sucrose by elution with 0.5 -percent phenol or 0.5 -percent ephedrine. Claesson [2] separated mixtures of glucose, sucrose, and raffinose by a similar procedure. Montgomery, Weakley, and Hilbert [3] isolated 6 -[ $\alpha$-D-glucopyranosyl]-D-glucose by chromatographic adsorption on Darco and selective elution of the enzymatic hydrolyzate of starch. As eluting agents these authors used water to remove the glucose and 0.5percent phenol to remove the disaccharide. Whistler and Durso [4] reported the selective elution of mono-, di-, and trisaccharides from Darco columns by means of water and water-ethanol mixtures. Selective adsorption and elution permit isolation of the individual sugars of a carbohydrate mixture.

The extensive use of sugar mixtures in food products has resulted in an increasing demand for more accurate and more rapid analytical methods in this field. Hydrol, the molasses of the dextrose industry; lactose, sucrose, and dextrose mixtures as found in infant foods, and liquid sugars of the sucrose industry are typical of these products.

The methods that are available for the analysis of corn sirups are unsuitable both because of the time required to carry them out and the unsatisfactory results obtained. These methods are based on the selective fermentation of dextrose in the presence of maltose and dextrins, or the selective reduction of a copper acetate solution by dextrose. The advantage offered by the procedure reported in this paper is that the dextrose and maltose are isolated and can then be determined as pure sugars. This separation of the sirup into its components is rapidly accomplished by passing the eluting agents through the column under 30 to 50 pounds of pressure. Satisfactory separation of dextrose, maltose, and dextrins can be accomplished in approximately $1 \frac{1}{2}$ hours.

\footnotetext{
${ }_{1}$ A general discussion of the selective adsorption of sugars and their derivatives is given in Chromatography of sugars and related substances by W. W. Binkley and M. L. Wolfrom, Scientific Report Series No. 10 (Sugar Research Foundation, Inc., New York, N. Y., 1948)

2 Fioures in brackets indicate the literature references at the end of this paper.
}

\section{Experimental Details}

The columns are Pyrex tubing of $34-\mathrm{mm}$ inside diameter (fig. 1). One standard length of glass (120 $\mathrm{cm}$ ) holds a column of adsorbent $200 \mathrm{~mm}$ high, together with $900 \mathrm{ml}$ of solution. One end of the tube is drawn down to a nipple about $3 \mathrm{~cm}$ long and $8 \mathrm{~mm}$ in diameter. To the other end is sealed a short length of Pyrex pipe, flanged on its free end. Connection to the pressure system is made with aluminum flanges sold by the manufacturer for use with Pyrex piping. One flange fits around the end of the column, and the other grips a piece of brass stock machined to the proper size and taper; through it is fed the one-quarter-in. copper tubing that connects to the reducing valve of the tank of nitrogen. A gasket of Koroseal separates the glass and brass surfaces at the joint. The copper tubing system is equipped with such valves as may be desirable for proper control of pressure. For simultaneous operation of the two columns it has been found convenient to have a cutoff

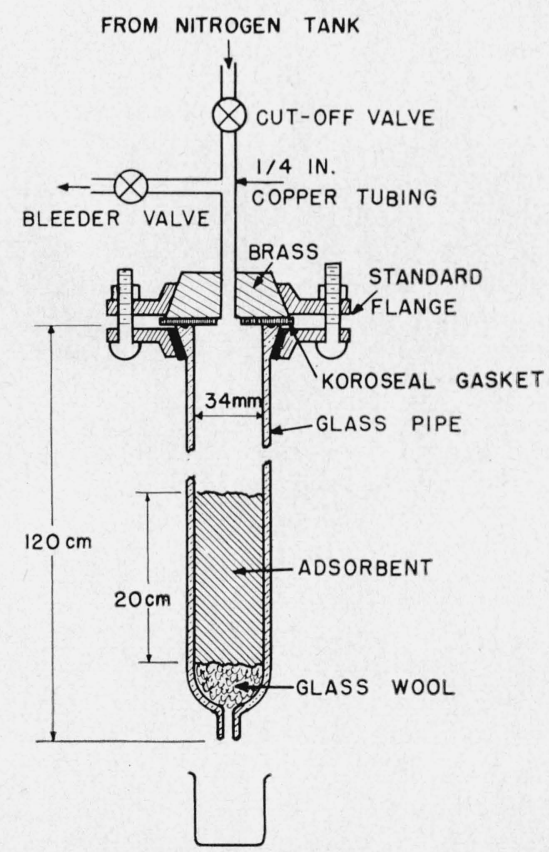

Figure: 1.-Diagram of column assembly. 


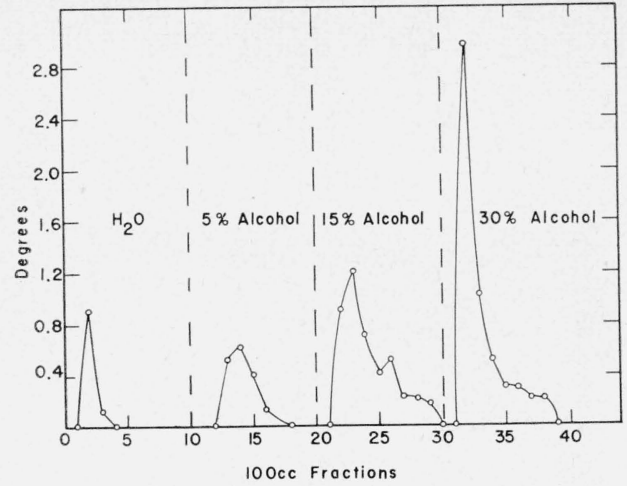

Figure 2. Polarimetric analysis of a corn sirup.

valve and a bleeder valve for each column. Since as much as $50 \mathrm{lb} / \mathrm{in}^{2}$ of pressure is applied, the columns are incased in an easily applied shield of split copper tubiag.

To fill the column a glass wool plug is placed at the bottom, and the tip of the column is then immersed in water so that the plug is thoroughly wet. This prevents the carbon particles from running through the glass wool during filling of the column. The adsorbent, composed of equal weights of Darco ${ }^{3}$ 60 (analytical grade) and Celite, is then poured into the column to a height of about one and one half times that desired for operation. It is packed by tapping lightly. The copper casing is then put in place, and connection to the pressure system is made. The column is washed with 2 or 3 liters of water. When the water level reaches that of the adsorbent, the pressure is released and the sugar sample added.

The sample to be analyzed is dissolved in 20 to 50 $\mathrm{ml}$ of water and added to the column. After the walls have been washed free of any adhering sugar solution, sufficient time is allowed for the level of the solution to reach that of the adsorbent; this may be accomplished either with or without increased pressure. About $900 \mathrm{ml}$, or one column, of water is then added. In preliminary experiments $100-\mathrm{ml}$ samples of the eluted solution are collected and the optical rotation of the individual fractions taken. This locates the fractions where dextrose, and subsequently maltose, may be expected to appear. Six hundred milliliters has been found adequate for removal of the dextrose; the remaining $300 \mathrm{ml}$ acts as a safety factor. Figure 2 is illustrative of such a run. Pressure is then released from the column, $900 \mathrm{ml}$ of 5percent ethanol ${ }^{4}$ is added, and the maltose is separated from the dextrins. The dextrins are then removed with more concentrated alcohol solution. Fifteen- and 30-percent alcohol fractions were collected in some experiments; however, a single fraction for dextrins seems sufficient. Upon completion of the run the column is cleaned with 95-percent alcohol; this has been found to remove all traces of carbohydrates. The alcohol is then washed out by a

\footnotetext{
${ }^{3}$ Darco is a vegetable carbon manufactured by the Darco Corp., New York, N. Y. Celite is a diatomaceous earth product manufactured by Johns Manville Corp., New York, N. Y.
}

${ }_{4}^{4} 5.2 \mathrm{ml}$ of 95 -percent alcohol per $100 \mathrm{ml}$ of solution column length of water, and the apparatus is ready for the next run.

As a general procedure it is desirable to collect the entire amount of each eluate in a single fraction, evaporate it under diminished pressure to a volume that can be made up to $100 \mathrm{ml}$, and make duplicate determinations on aliquot portions. This permits fewer analyses on a given fraction and larger quantities of sugar in each determination.

\section{Results}

A series of analyses of dextrose-maltose mixtures of known composition was made in order to ascertain the accuracy of the method. The recovery of sugar obtained in these determinations is given in table 1. It was found that the percentage recovery was not effected whan pressures up to $50 \mathrm{lb} /$ in. $^{2}$ were used to increase the rate of flow of the eluting agents; higher pressures were not investigated. It is suggested that a correction factor be determined by analyzing a known dextrose-maltose mixture under the same experimental conditions that are to be used for the sirup analysis. This factor will be in the range of 3 percent of the weight of each sugar and will be a function of the individual column and the eluting agent.

Paper chromatographs indicated that the dextrose, maltose, and dextrin fractions as separated were not contaminated with the other sugars present in the dextrose-maltose mixtures or sirups. The chromatographs were run by the method described by Partridge [5]. The solvent consisted of ethyl acetate 250 , pyridine 70 , and water 85 parts by volume. The chromatographs were run 16 to 24 hours on Whatman No. 1 filter paper. Ammoniacal silver nitrate solution was sprayed on the air-dried paper to indicate the position of the sugars.

TABle 1. Separation of dextrose-maltose mixtures on Darco

\begin{tabular}{|c|c|c|c|c|c|c|}
\hline \multirow{2}{*}{ Method of analysis } & \multicolumn{3}{|c|}{ Dextrose } & \multicolumn{3}{|c|}{ Maltose } \\
\hline & Present & Found & $\begin{array}{c}\text { Re- } \\
\text { covery }\end{array}$ & Present & Found & $\begin{array}{c}\text { Re- } \\
\text { covery }\end{array}$ \\
\hline Polarization & $\left\{\begin{array}{c}g \\
0.5021 \\
1.0004\end{array}\right.$ & $\begin{array}{c}g \\
0.4803 \\
.9506\end{array}$ & $\begin{array}{l}\% \\
95.66 \\
96.02\end{array}$ & $\begin{array}{c}g \\
0.5010 \\
1.0040\end{array}$ & $\begin{array}{c}g \\
0.4781 \\
.9458\end{array}$ & $\begin{array}{l}\% \\
95.4 \\
94.2\end{array}$ \\
\hline A verage _ & $\ldots$ & $\ldots$ & 95.7 & ........ & $\ldots$ & 94,8 \\
\hline $\begin{array}{l}\text { Munson and Walker } \\
\text { reducing sugar } \\
\text { method. }\end{array}$ & $\left\{\begin{array}{l}.6082 \\
.34105 \\
.2736 \\
.2736\end{array}\right.$ & $\begin{array}{l}.5801 \\
.3229 \\
.2748 \\
.2608\end{array}$ & $\begin{array}{r}95.39 \\
94.68 \\
100.40 \\
95.35\end{array}$ & $\begin{array}{l}.6416 \\
.3502 \\
.4450 \\
.4450\end{array}$ & $\begin{array}{l}.6323 \\
.3363 \\
.4353 \\
.4275\end{array}$ & $\begin{array}{l}98.55 \\
96.03 \\
97.82 \\
96.07\end{array}$ \\
\hline A verage & & . & 96.45 & & & 97.12 \\
\hline
\end{tabular}

After separation of the sugars on the column, analyses of the respective fractions were made either by direct polarization or by Munson and Walker's reducing sugar method. There appears to be no relation between the size of the sample and the percentage recovery, showing that all samples are within the loading capacity of the column. In general, it may be said that the reducing sugar method is the more accurata means of analysis. 
Here an error of \pm 0.3 percent is to be expected, while in the case of polarimetric analysis an error of \pm 0.05 degrees in reading the polarimeter appears as an error of 1.7 percent in the determination of $0.5 \mathrm{~g}$ of dextrose in $100 \mathrm{ml}$ of solution (4-dm polarimeter tube).

When cocoanut char was used in place of Darco, it was found that the dextrose was removed quantitatively by 5-parcent aqueous alcohol and the maltose by 10-percent alcohol However, when samples of corn sirups were introduced, the maltose and dextrins were not sharply separated. Further studies with eluting agents are required with this char. Norit also requires 5-percent alcohol to remove the dextrose, and here again the separation is not sharp when sirups are introduced.

Six corn sirups were separated on Darco columns, the final analysis being made by both Munson and Walker's method and by use of a polarimeter. Their dextrose equivalents, as determined by Lane and Eynon's method, ranged from 30.6 to 80.7 based on total solids. The dextrins are reported as dextrose equivalents in the reducing sugar procedure, and in degrees of rotation per gram of sirup in the polarization analysis; it is not to be expected that the results obtained by the two methods of analysis will be interconvertible. It is noteworthy that the dextrins possess considerable reducing power when Fehling solution is used as in the method of Munson and Walker. The results of the analysis of the six sirups are summarized in table 2 .

TABLE 2. Corn sirup analysis by use of Darco-Celite columns

\begin{tabular}{|c|c|c|c|c|c|c|c|}
\hline \multirow{3}{*}{ Sirup } & \multirow{3}{*}{$\begin{array}{l}\text { Dextrose } \\
\text { equiva- } \\
\text { lents } \\
\text { based on } \\
\text { whole } \\
\text { sirup }\end{array}$} & \multicolumn{6}{|c|}{ Method of sugar analysis } \\
\hline & & \multicolumn{3}{|c|}{ Munson and Walker } & \multicolumn{3}{|c|}{ Polarimeter } \\
\hline & & $\begin{array}{l}\text { Dex- } \\
\text { trose }\end{array}$ & $\begin{array}{l}\text { Mal- } \\
\text { tose }\end{array}$ & $\begin{array}{l}\text { Dextrins } \\
\text { (as dex- } \\
\text { trose) }\end{array}$ & $\begin{array}{l}\text { Dex- } \\
\text { trose }\end{array}$ & $\begin{array}{l}\text { Mal- } \\
\text { tose }\end{array}$ & $\begin{array}{l}\text { Dex- } \\
\text { trins }\end{array}$ \\
\hline 1 & \multirow{2}{*}{24.3} & $\begin{array}{c}\text { Per- } \\
\text { cent }{ }^{a}\end{array}$ & Percent & Percent & Percent & Percent & $\begin{array}{l}\text { Degrees } \\
\text { per g of } \\
\text { sirup }\end{array}$ \\
\hline \multirow[t]{2}{*}{2} & & $\begin{array}{l}14.7 \\
14.8 \\
14.5\end{array}$ & $\begin{array}{l}11.7 \\
11.95 \\
11.95\end{array}$ & $\begin{array}{r}10.8 \\
7.9\end{array}$ & $\begin{array}{r}4.8 \\
16.6 \\
16.5 \\
13.4\end{array}$ & $\begin{array}{r}2.9 \\
10.3 \\
8.8 \\
9.2\end{array}$ & - \\
\hline & 32.5 & 14.6 & 11.7 & & & & \\
\hline 3 & 33.5 & $\begin{array}{l}15.1 \\
26.9\end{array}$ & $\begin{array}{l}13.7 \\
16.3\end{array}$ & $\begin{array}{r}10.9 \\
9.5\end{array}$ & $\begin{array}{l}17.0 \\
27.3\end{array}$ & $\begin{array}{l}16.6 \\
14.6\end{array}$ & $\begin{array}{l}4.6 \\
3.5\end{array}$ \\
\hline \multirow[t]{2}{*}{4} & \multirow[t]{2}{*}{45.5} & $\begin{array}{l}26.9 \\
27.2\end{array}$ & $\begin{array}{l}16.4 \\
16.6\end{array}$ & $\begin{array}{l}9.3 \\
7.9\end{array}$ & $\cdots$ & $\cdots$ & (n...... \\
\hline & & 27.4 & 15.4 & 8.8 & & & \\
\hline 5 & 48.1 & $\begin{array}{l}30.6 \\
30.1\end{array}$ & $\begin{array}{l}17.6 \\
16.6\end{array}$ & (n) & 30.6 & 17.5 & 3.1 \\
\hline 6 & 61.3 & 56.7 & 14.4 & - & 56.4 & 13.4 & 1.0 \\
\hline
\end{tabular}

${ }^{a}$ All percentages are based on whole sirup.

Sirups of different concentration may be compared by graphs similar to those in figures 3 and 4 , since these results are based on samples containing $1 \mathrm{gram}$ of dry substance. ${ }^{5}$ The direct rotation of each fraction after concentration to $100 \mathrm{ml}$ is represented on the ordinate of figure 3 . Such a graph gives an over-all picture of a sirup and is of value for comparison purposes in the consideration of different products. The percentage content of dextrose and

${ }_{5}$ We express our appreciation to C. F. Snyder for the dry substance analyses.

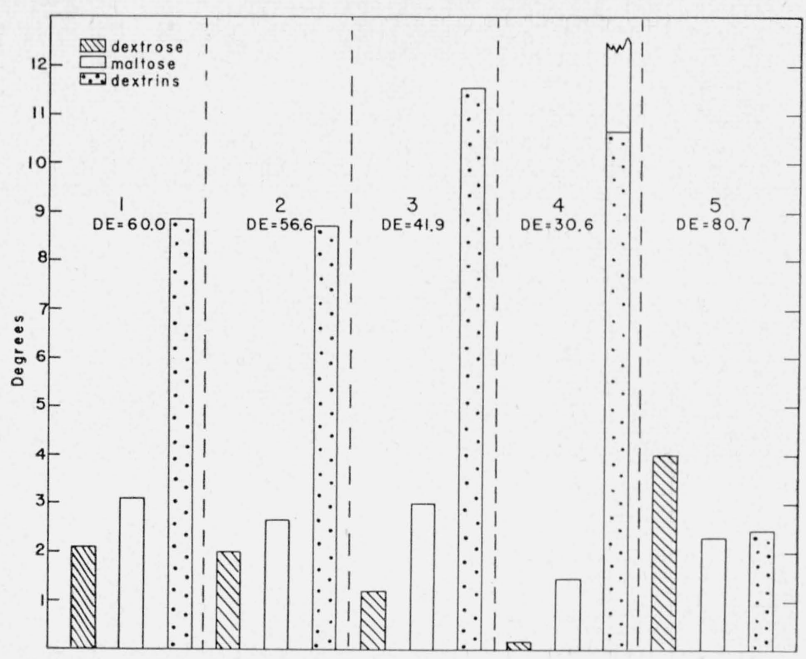

Figure 3. Polarimetric analysis of five corn sirups.

Direct rotation of $1 \mathrm{~g}$ of dry substance in $100 \mathrm{ml}$ of solution. DE indicates dextrose equivalent.

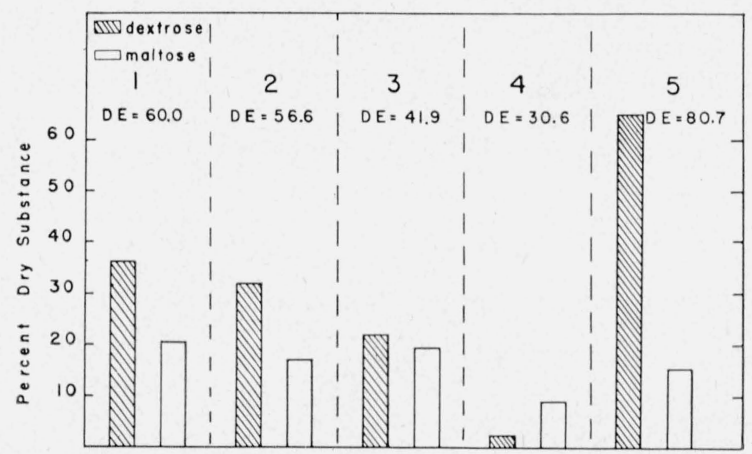

Figure 4. Dextrose and maltose content of five corn sirups. $\mathrm{DE}$ indicates dextrose equivalent.

maltose as shown in figure 4 is based upon reducingsugar analysis. Dextrins are not included in the figure since they can not be determined directly.

In order to compare the proposed method with the most accurate procedure available, sirup 4 , table 2 , was also analyzed by a method used by F. W. Zerban, ${ }^{6}$ who has kindly made the following description available:

The total reducing power of the original sirup is determined by means of Fehling solution, and the result expressed as glucose. The reducing power is again determined in the residue after fermentation with baker's yeast, against Fehling solution and also against the Steinhoff copper acetate reagent; the results are expressed as glucose. The difference between the results with Fehling solution, before and after fermentation, gives the sum of glucose and maltose hydrate, expressed as glucose (1st approximation). The glucose originally present in the sirup is determined by Steinhoff's copper acetate reagent, and corrected for the apparent glucose found in the unfermentable residue by the same method. This corrected glucose is then deducted from the sum of glucose and maltose hydrate, expressed as glucose found in the 1st approximation. This gives the maltose hydrate, expressed as glucose (1st approximation). It is converted into maltose hydrate on the basis of the 
reducing ratio of glucose to maltose hydrate, and the glucose is corrected for the reducing power of the maltose hydrate on the Steinhoff copper acetate reagent. The corrected glucose is subtracted from the sum of glucose and maltose hydrate expressed as glucose, previously found, and the approximations are repeated until there is no further change in the glucose and maltose values.

The composition of the sirup found by the two methods are:

\begin{tabular}{|l|l|}
\hline Zerban's procedure_.... & $\left\{\begin{array}{l}\text { Dextrose, } 27.0 \text { percent. } \\
\text { Maltose, 19.0 percent. }\end{array}\right.$ \\
Darco-Celite column_... & $\left\{\begin{array}{l}\text { Dextrose, 27.2 percent. } \\
\text { Maltose, } 16.2 \text { percent. } \\
\text { Dextrins, } 8.9 \text { percent. }{ }^{a}\end{array}\right.$ \\
\hline
\end{tabular}

a Expressed as dextrose.

The two methods show good agreement for the dextrose content. It is evident that the dextrin portion contains an unfermentable fraction that has a reducing power equivalent to 8.9 percent of dextrose. Although this material does not interfere with the copper acetate reduction, it reduces Fehling solution, thereby causing the discrepancy in the maltose analyses.

If the alcohol concentration of the eluting agent is increased in several steps between 5 and 30 percent, the dextrins can be divided into triose, tetrose, and higher polysaccharides [6]. However for analytical purposes where time is important, it appears that the procedure here described gives the information that is necessary for characterizing a corn sirup. Studies are now in progress to extend the method to include sucrose and invert sugar in the mixtures.

\section{References}

[1] A. Tiselius, Kolloid Z. 105, 101 (1943).

[2] S. Claesson, Arkiv. Kimi, Mineral Geol. 24A, No. 16 (1947).

[3] E. Montgomery, F. B. Weakley, and G. E. Hilbert, J. Am. Chem. Soc. $\boldsymbol{7 1}, 1682$ (1949).

[4] R. L. Whistler and F. Durso, J. Am. Chem. Soc. 72, 677 (1950).

[5] S. M. Partridge, Biochem. J. 42, 238 (1948).

[6] J. M. Bailey, W. J. Whelan, and S. Peat, J. Chem. Soc. (1950) 3692 .

Washington, May 1, 1951 